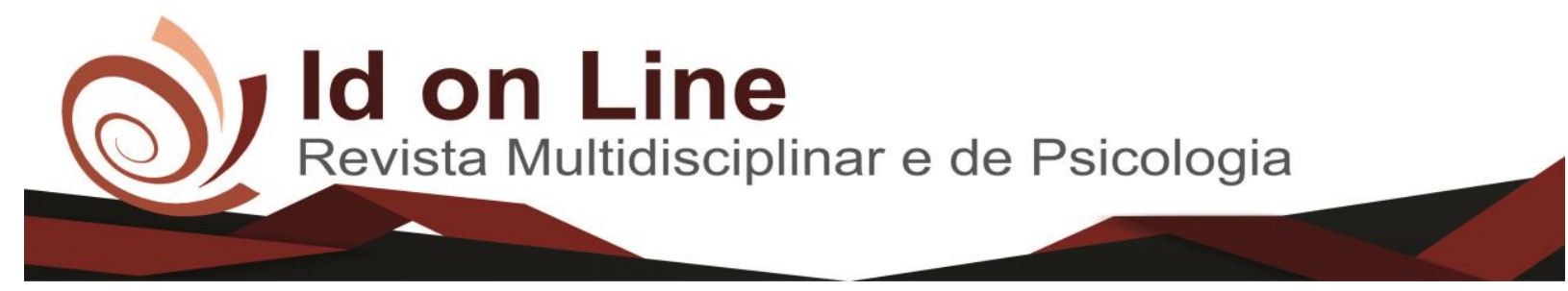

Estudo de Revisão

\title{
O Cirurgião-Dentista e o Mercado de Trabalho no Brasil: Uma Revisão Sistemática da Literatura
}

Danilo Sales Costa ${ }^{I}$; Marcelo Pereira da Rocha ${ }^{2}$

\begin{abstract}
Resumo: Introdução: O mercado de trabalho para o Cirurgião-Dentista (CD), no Brasil, vem passando por diversas mudanças, tendo em vista questões importantes de ordem econômica e do modelo de atenção em saúde bucal. Objetivo: realizar revisão da literatura acerca do mercado de trabalho para os CD. Métodos: Trata-se de estudo de revisão sistemática da literatura, sobre o mercado de trabalho em odontologia, no Brasil, por meio de acesso às bases de dados da Biblioteca Virtual em Saúde, e Portal Capes. Resultados: O Brasil possui elevado número de profissionais, acima do preconizado pela Organização Mundial de Saúde. Predomina o gênero feminino e vem crescendo o número de especialistas. O serviço público carece de melhores condições de trabalho. Conclusão: O dentista precisa se capacitar para atender as necessidades do mercado, pois há grande concorrência na profissão. O Ministério da Saúde precisa atuar na regulação da formação dos profissionais, para atender as necessidades de saúde da população.
\end{abstract}

Palavras-chave: Mercado de trabalho; dentista; Brasil.

\section{The Dentist and the Labor Market in Brazil: A Systematic Review of the Literature}

\begin{abstract}
Introduction: The labor market for the dentist in Brazil has undergone several changes, considering important economic issues and the model of oral health care. Objective: to carry out a literature review about the labor market for dentist. Methods: This is a systematic review of the literature on the job market in dentistry in Brazil, through access to the databases of the Virtual Health Library and Portal Capes. Results: Brazil has a high number of professionals, higher than those recommended by the World Health Organization. Women predominate and the number of specialists is growing. The public service needs better working conditions. Conclusion: The dentist needs to be trained to meet the needs of the market as there is great competition in the profession. The Ministry of Health needs to act in the regulation of the training of professionals, to meet the health needs of the population.
\end{abstract}

Keywords: Job market; dentist; Brazil.

\footnotetext{
${ }^{1}$ Acadêmico do curso de Odontologia da Faculdade Independente do Nordeste (FAINOR). Contato: dansales@ live.com, Vitória da Conquista, Bahia, Brasil.

${ }^{2}$ Mestre em Saúde Coletiva, Docente do Curso de Odontologia da Faculdade Independente do Nordeste (FAINOR). Contato: cdbiomarcelo@yahoo.com.br, Vitória da Conquista, Bahia, Brasil
} 


\section{Introdução}

O mercado de trabalho para o Cirurgião-Dentista (CD), no Brasil, vem passando por diversas mudanças, tendo em vista questões importantes de ordem econômica e do modelo de atenção em saúde bucal. Nos últimos anos houve maior oferta de vagas nos cursos de graduação, interiorização das universidades, antes concentradas nos grandes centros e capitais e ampliação dos postos de trabalho no Sistema Único de Saúde (SUS) (Mathias et al,. 2016).

O perfil do profissional (CD) está em constante modificação. Machado et al, descreveram que há o predomínio de profissionais autônomos, apesar da considerável diminuição dessa forma de inserção no mercado de trabalho. Durante muitas décadas, a odontologia voltou o seu modelo de trabalho para a prática individual, na qual a relação existente era apenas entre o profissional e seu paciente. Um modelo tecnicista, centrado na doença, com ênfase em práticas curativas, de cunho liberal e elitista (Pinheiro 2011).

Merece destacar a necessidade de formação de profissionais aptos a trabalhar SUS, levando-se em conta que no Brasil é direito de todas as pessoas terem acesso integral à saúde (Brasil, Constituição 1988). Para tanto, há a necessidade de formação do aluno humanista e crítico, capaz de atuar em todos os níveis de atenção à saúde bucal da população, buscando-se a transformação da realidade social (CNE, 2002). Além da esfera pública, o CD pode atuar em serviços privados, bem como no ensino e pesquisa, dentre outras possibilidades.

Destaca-se ainda a crescente precarização do trabalho no Brasil. Isso também reflete no sistema público, além da esfera privada, com a introdução de medidas de flexibilização das relações trabalhistas, com novas formas de contratação e perdas de direitos, tendo como consequências, insatisfação e adoecimento de trabalhadores, o que pode refletir na qualidade do cuidado aos usuários dos serviços (Faria et al,. 2011).

A Pergunta principal que esta pesquisa buscou responder foi: quais são os principais aspectos retratados nos estudos acerca do mercado de trabalho no Brasil para os CD? Não foram encontrados trabalhos de revisão sistemática da literatura dentro dessa temática. Por isso, evidenciou-se a necessidade de pesquisar sobre o assunto. O objetivo deste estudo foi realizar uma revisão sistemática da literatura acerca do mercado de trabalho para os $\mathrm{CD}$, no Brasil. 


\section{Método}

Trata-se de de estudo de revisão sistemática da literatura, acerca do mercado de trabalho em odontologia no Brasil, por meio de acesso às bases de dados da Biblioteca Virtual em Saúde (BVS), e Portal Capes. Ressalta-se a grande abrangência da BVS, pois reúne publicações de outras bases de dados da área de saúde, como Lilacs, Ibecs, Medline, Cochrane e SciELO. Portanto, se constitui em adequada ferramenta para revisão sistemática (Santos e Assis, 2011).

Foram utilizados os seguintes descritores: mercado de trabalho, dentista e Brasil. A seleção e avaliação dos artigos foram realizadas por pares. Os critérios de inclusão usados foram: publicações em formato de artigo, sem restrição de período de publicação e de idioma, e resultantes de estudos produzidos no Brasil. Foram excluídos trabalhos que fugiram da temática proposta, em formato diferente de artigo, como teses, e que não atenderam aos critérios acima elencados.

Após o acesso às bases de dados, foram lidos os títulos, objetivando-se retirar estudos duplicados e selecionar os trabalhos para a pesquisa. Seguindo-se, foi realizada a leitura dos resumos, para escolha dos estudos elegíveis. Esses trabalhos passaram por leitura completa. Após a leitura, foram incluídos trabalhos que atenderam a um ou mais dos seguintes critérios: retrataram a situação do mercado de trabalho; trataram da formação profissional e sua contribuição para a inserção no mercado de trabalho.

Após a leitura dos artigos, alguns dados e informações foram sistematizados em quadro 1. Os dados foram analisados de forma descritiva.

Quadro 1: Síntese dos artigos acerca do mercado de trabalho do Cirurgião-Dentista no Brasil, Biblioteca Virtual em Saúde e Portal Capes, 2017.

\begin{tabular}{|l|l|l|l|}
\hline \multicolumn{1}{|c|}{ Título } & $\begin{array}{c}\text { Autores, } \\
\text { periódico; local do } \\
\text { estudo e Base de } \\
\text { dados. }\end{array}$ & \multicolumn{1}{|c|}{ Metodologia } & \multicolumn{1}{c|}{$\begin{array}{c}\text { Principais } \\
\text { resultados/conclusões }\end{array}$} \\
\hline $\begin{array}{l}\text { Revisão e discussão } \\
\text { sobre indicadores para a } \\
\text { previsão de demanda } \\
\text { por cirurgiões-dentistas } \\
\text { no Brasil. }\end{array}$ & $\begin{array}{l}\text { Lucietto, DA. Filho, } \\
\text { AA, Oliveira SP. }\end{array}$ & $\begin{array}{l}\text { Análise bibliográfica e } \\
\text { documental. }\end{array}$ & $\begin{array}{l}\text { Má distribuição dos CD no } \\
\text { País. Levando em } \\
\text { consideração o preconizado } \\
\text { pelo Ministério da Saúde, } \\
\text { evidencia-se a necessidade de } \\
\text { um grande número de novos }\end{array}$ \\
\hline
\end{tabular}




\begin{tabular}{|c|c|c|c|}
\hline & Base: Portal Capes & & $\begin{array}{l}\text { postos de trabalho em saúde } \\
\text { pública, de modo a garantir a } \\
\text { universalidade de acesso aos } \\
\text { serviços odontológicos. }\end{array}$ \\
\hline $\begin{array}{l}\text { Adequação de recursos } \\
\text { humanos ao PSF: } \\
\text { percepção de } \\
\text { formandos de dois } \\
\text { modelos de formação } \\
\text { acadêmica em } \\
\text { odontologia. }\end{array}$ & $\begin{array}{l}\text { Sanchez, } \\
\text { Drummond, } \\
\text { Vilaça, RL. } \\
\text { Ciênc. Saúde coletiva, } \\
\text { 2008. } \\
\text { Minas Gerais } \\
\text { Base: Portal Capes }\end{array}$ & $\begin{array}{l}\text { Aplicação de } \\
\text { questionário. }\end{array}$ & $\begin{array}{l}\text { Predominou entre os } \\
\text { acadêmicos o desejo de } \\
\text { trabalhar no PSF, devido à } \\
\text { dificuldades do mercado de } \\
\text { trabalho. }\end{array}$ \\
\hline $\begin{array}{l}\text { Analise do mercado de } \\
\text { trabalho odontológico } \\
\text { na região do nordeste } \\
\text { do Brasil. }\end{array}$ & $\begin{array}{l}\text { Paranhos, LR. } \\
\text { Ricci ID, } \\
\text { Siqueira DF, } \\
\text { Scanavini MA, } \\
\text { Júnior } \\
\text { Revista de Odontologia } \\
\text { da Universidade Cidade } \\
\text { de São Paulo, } 2009 . \\
\text { Região Nordeste. } \\
\text { Base: BVS }\end{array}$ & $\begin{array}{l}\text { Análise de dados do } \\
\text { CFO e IBGE. }\end{array}$ & $\begin{array}{l}\text { Os Estados da Região } \\
\text { Nordeste do Brasil apresentam } \\
\text { índices maiores que o } \\
\text { recomendado pela } \\
\text { Organização Mundial de } \\
\text { Saúde (1:1.500), com exceção } \\
\text { da Paraíba e do Rio Grande do } \\
\text { Norte que apresentam maior } \\
\text { proporção entre habitantes por } \\
\text { CD. }\end{array}$ \\
\hline $\begin{array}{l}\text { Analise do mercado de } \\
\text { trabalho odontológico } \\
\text { na região Sul do Brasil. }\end{array}$ & $\begin{array}{l}\text { Paranhos, LR. } \\
\text { Ricci, ID. } \\
\text { Scanavini, MA. } \\
\text { Bérzin, F. } \\
\text { Ramos, AL. } \\
\text { RFO, 2009 } \\
\text { Região Sul. } \\
\text { Base: BVS }\end{array}$ & $\begin{array}{l}\text { Análise de dados do } \\
\text { CFO e IBGE. }\end{array}$ & $\begin{array}{l}\text { Os estados da região sul do } \\
\text { Brasil apresentaram proporção } \\
\text { CD (CD)/especialista: } \\
\text { habitantes maiores que o } \\
\text { recomendado pela } \\
\text { Organização Mundial da } \\
\text { Saúde }(1: 1.500) \text {. }\end{array}$ \\
\hline $\begin{array}{l}\text { Analise do mercado de } \\
\text { trabalho odontológico } \\
\text { na região Sudeste do } \\
\text { Brasil. }\end{array}$ & $\begin{array}{l}\text { Paranhos, L.R. Ramos, } \\
\text { A.L. Scanavini, M.A. } \\
\text { Ricci, I.D. } \\
\text { Res. Assoc. Paul. Cir. } \\
\text { Dent. 2009. } \\
\text { Região Sudeste. } \\
\text { Base: BVS }\end{array}$ & $\begin{array}{l}\text { Análise de dados do } \\
\text { CFO e IBGE. }\end{array}$ & $\begin{array}{l}\text { Todos os estados da Região } \\
\text { Sudeste do país apresentaram } \\
\text { proporção de CD acima do } \\
\text { recomendado pela OMS. Essa } \\
\text { região concentrava } 56,16 \% \text { do } \\
\text { total de especialistas de todo o } \\
\text { Brasil, englobando as } \\
\text { diferentes áreas de atuação. }\end{array}$ \\
\hline $\begin{array}{l}\text { Análise do mercado de } \\
\text { trabalho odontológico } \\
\text { na região norte do } \\
\text { Brasil }\end{array}$ & $\begin{array}{l}\text { Paranhos, L.R. } \\
\text { I.D. Ficci, } \\
\text { Castro. R. R.P.A. } \\
\text { M.A. } \\
\text { Revista Odonto. } \\
\text { 2009. } \\
\text { Região Norte } \\
\text { Base: BVS }\end{array}$ & $\begin{array}{l}\text { Análise de dados do } \\
\text { CFO e IBGE. }\end{array}$ & $\begin{array}{l}\text { O mercado de trabalho para os } \\
\text { especialistas da região norte } \\
\text { para Pacientes com } \\
\text { Necessidades Especiais, } \\
\text { Odontologia do Trabalho e da } \\
\text { Estomatologia apresentava-se } \\
\text { com melhor proporção de } \\
\text { especialista/habitante, } \\
\text { enquanto as áreas de } \\
\text { Ortodontia e Endodontia } \\
\text { apresentam maior proporção } \\
\text { especialista/habitante. }\end{array}$ \\
\hline $\begin{array}{l}\text { Análise do mercado de } \\
\text { trabalho odontológico } \\
\text { na região centro-oeste } \\
\text { do Brasil }\end{array}$ & 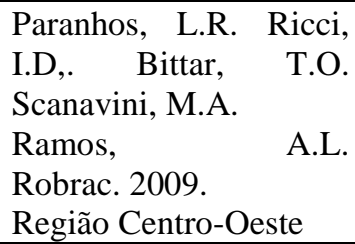 & $\begin{array}{l}\text { Análise de dados do } \\
\text { CFO e IBGE. }\end{array}$ & $\begin{array}{l}\text { Apresentaram proporção de } \\
\text { CD/habitante maiores do que } \\
\text { o recomendado pela } \\
\text { Organização Mundial de } \\
\text { Saúde }(1: 1.500) \text {, com exceção } \\
\text { do Distrito Federal que }\end{array}$ \\
\hline
\end{tabular}




\begin{tabular}{|c|c|c|c|}
\hline & Base: BVS. & & $\begin{array}{l}\text { apresenta maior proporção } \\
\text { entre habitantes por CD }\end{array}$ \\
\hline $\begin{array}{l}\text { A inserção de equipes } \\
\text { de saúde bucal no } \\
\text { Programa Saúde da } \\
\text { Família no Estado de } \\
\text { Minas Gerais }\end{array}$ & $\begin{array}{l}\text { Lourenço, E.C,. Silva, } \\
\text { A.C.B. Meneghin, M.C. } \\
\text { Pereira, A.C. } \\
\text { Ciência \& Saúde } \\
\text { Coletiva, 2009. } \\
\text { Minas Gerais } \\
\text { Base: Portal Capes }\end{array}$ & $\begin{array}{l}\text { Realizado em } 310 \\
\text { municípios de Minas } \\
\text { Gerais, utilizando-se } \\
\text { questionários. }\end{array}$ & $\begin{array}{l}\text { Discrepância de salário entre } \\
\text { médicos e dentistas. Falta de } \\
\text { capacitação adequada das } \\
\text { Equipes de Saúde Bucal, } \\
\text { demanda excessiva e } \\
\text { precarização das relações de } \\
\text { trabalho. }\end{array}$ \\
\hline $\begin{array}{l}\text { Satisfação e sofrimento } \\
\text { no trabalho do } \\
\text { cirurgião-dentista }\end{array}$ & $\begin{array}{l}\text { Gomes, D. Gonçalves, } \\
\text { A.S.R. Pereira, L.S. } \\
\text { Tavares, R.S. Pires, } \\
\text { D.E.P. Ramos, F.R.S. } \\
\text { RFO, } 2010 \quad \text { Catarina. } \\
\text { Santa } \\
\text { Base: BVS }\end{array}$ & $\begin{array}{l}\text { Os dados foram } \\
\text { coletados por meio de } \\
\text { entrevistas a dezesseis } \\
\text { cirurgiões-dentistas que } \\
\text { atuavam na rede básica } \\
\text { de saúde de um } \\
\text { município da região Sul } \\
\text { do Brasil. }\end{array}$ & $\begin{array}{l}\text { Elementos complexos estão } \\
\text { envolvidos no processo de } \\
\text { trabalho dos profissionais, } \\
\text { sejam ligados à própria } \\
\text { profissão, sejam aos desafios } \\
\text { atuais da organização do } \\
\text { trabalho coletivo na atenção } \\
\text { básica. }\end{array}$ \\
\hline $\begin{array}{l}\text { Inserção dos egressos } \\
\text { do curso de odontologia } \\
\text { no mercado de trabalho }\end{array}$ & 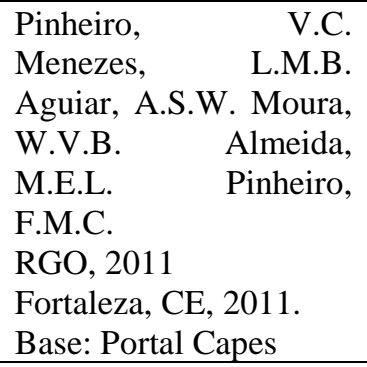 & $\begin{array}{l}\text { Aplicação de } \\
\text { questionário com } \\
\text { profissionais no ano de } \\
2009, \text { traçando o perfil } \\
\text { sócio- demográfico, dos } \\
\text { CD formados em 2007, } \\
\text { na Universidade } \\
\text { Federal do Ceara. }\end{array}$ & $\begin{array}{l}\text { Boa inserção dos recém- } \\
\text { formados no mercado de } \\
\text { trabalho. Os CD perceberam o } \\
\text { mercado de trabalho como } \\
\text { bom e normal e ainda } \\
\text { mostraram-se satisfeitos com a } \\
\text { profissão escolhida. }\end{array}$ \\
\hline $\begin{array}{l}\text { A Odontologia no } \\
\text { contexto do Sistema } \\
\text { Único de Saúde de } \\
\text { Montes Claros, Minas } \\
\text { Gerais, Brasil. }\end{array}$ & $\begin{array}{l}\text { Coelho, M.Q, Costa, } \\
\text { S.M. Martelli, D.R.B. } \\
\text { Junior, H.M. Bonan, } \\
\text { P.R.F. Francy, S. } \\
\text { Arq. Odontol., 2011 } \\
\text { Montes Claros, MG, } \\
\text { 2011. } \\
\text { Base: Portal Capes }\end{array}$ & $\begin{array}{l}\text { Aplicação de } \\
\text { questionário feito com } \\
94 \text { CD do setor publico } \\
\text { do município de } \\
\text { Montes Claros, } \\
\text { abordando variáveis do } \\
\text { perfil e exercício } \\
\text { profissional na Atenção } \\
\text { Primaria à Saúde. }\end{array}$ & $\begin{array}{l}\text { Os entrevistados tinham de } 25 \\
\text { a } 34 \text { anos. } 61,7 \% \text { dos CDs } \\
\text { entrevistados eram do sexo } \\
\text { feminino. Os formados há } \\
\text { menos de } 10 \text { anos eram } \\
36,2 \% \text {. A maioria não } \\
\text { apresentou dificuldades no } \\
\text { exercício da profissão, uma } \\
\text { vez que a grande maioria } \\
\text { relatou já ter feito treinamento } \\
\text { em serviço a ter formação } \\
\text { recente. }\end{array}$ \\
\hline $\begin{array}{l}\text { Relações contratuais e } \\
\text { perfil dos cirurgiões } \\
\text { dentistas em centros de } \\
\text { especialidades } \\
\text { odontológicas de baixo } \\
\text { e alto desempenho no } \\
\text { Brasil. }\end{array}$ & $\begin{array}{l}\text { Oliveira, R.S. Morais, } \\
\text { H.M.M. Góes, P.S.A. } \\
\text { Botazzo, C. } \\
\text { Magalhães, B.G. } \\
\text { Saúde Soc. 2015. } \\
\text { Cinco Macrorregiões, } \\
\text { Brasil, } 2015 . \\
\text { Base: Portal Capes }\end{array}$ & $\begin{array}{l}\text { Entrevistas semi } \\
\text { estruturadas com } 289 \\
\text { profissionais em } 59 \\
\text { centros de } \\
\text { especialidades } \\
\text { odontológicas das } 5 \\
\text { macrorregiões do país, } \\
\text { selecionados entre os } \\
10 \% \text { com melhor e pior } \\
\text { desempenho. }\end{array}$ & $\begin{array}{l}55 \% \text { dos profissionais } \\
\text { entrevistados eram do sexo } \\
\text { feminino. } 72,7 \% \text { estavam } \\
\text { fazendo pós-graduação no } \\
\text { momento da entrevista. } \\
\text { Mesmo os CD sendo } \\
\text { qualificados para o CEO, } \\
\text { identificaram baixa } \\
\text { remuneração e precariedade } \\
\text { de vínculos de trabalho. }\end{array}$ \\
\hline
\end{tabular}

Fonte : Autores 


\section{Resultados}

\section{Perfil dos trabalhos selecionados}

Após acesso às bases de dados, foram encontradas 26 publicações indexadas na BVS, das quais seis foram selecionadas, dentro dos critérios estabelecidos. Na busca no Portal Capes foram encontrados 380 trabalhos. No entanto, poucos atenderam aos critérios estabelecidos, principalmente por não tratarem da temática em questão. Por isso, foram selecionados seis artigos dessa base. No total foram contempladas neste estudo 12 publicações (Quadro 1). Todos os artigos foram publicados em periódicos brasileiros e na língua portuguesa. Além disso, todas as autorias foram múltiplas. Um mesmo autor participou de cinco publicações, voltadas para estudos regionais acerca da demanda de CD generalistas e especialistas.

Quanto ao local de realização dos estudos, houve estudos abrangendo todas as regiões do Brasil. As regiões Sul, Sudeste e Nordeste apresentaram mais estudos, dois em cada região, perfazendo-se 50\% dos estudos. Quanto ao período de publicação, variou de 2008, a mais antiga a 2015, a mais recente. Metade dos estudos foram publicados em 2009.

Quanto à metodologia utilizada, um estudo foi de revisão da literatura, cinco estudos utilizaram análise documental e seis estudos foram baseados em entrevistas. Quanto ao periódico, dois estudos foram publicados na revista RFO e dois na Ciência e Saúde Coletiva. Os demais artigos foram de revistas distintas.

\section{Principais aspectos dos trabalhos}

\section{Necessidade e distribuição dos profissionais}

Alguns trabalhos encontrados trataram da necessidade de profissionais e a distribuição desses, por região do País. Pesquisa realizada em 2008, teve o objetivo de discutir a demanda por CD, a partir do indicador da Organização Mundial de Saúde (OMS) e a necessidade de profissionais para a Estratégia de Saúde da Família (ESF). Foi detectado um contingente grande de CD (acima do preconizado pela OMS) e concentração desigual nos diferentes 
Estados e Regiões. No entanto, quando se levou em conta a proposta do Ministério da Saúde em universalizar os serviços do SUS para todos os brasileiros, concluíram que seriam necessários mais profissionais. Identificaram a necessidade de problematizar a questão no interior da classe odontológica, pois a incoerência entre as necessidades de mercado e a oferta crescente de $\mathrm{CD}$ poderia trazer consequências indesejáveis, tanto para os profissionais quanto para os usuários (Lucietto et al,. 2008).

Foi avaliada a relação (CD)/habitante e a distribuição dos especialistas em odontologia, na região Nordeste do Brasil. Utilizaram-se dados do Conselho Federal de Odontologia (CFO), de 2007, e do Instituto Brasileiro de Geografia e Estatística (IBGE). Os estados da região Nordeste, exceto Paraíba e do Rio Grande do Norte, possuíam elevada proporção de CD, acima do sugerido pela OMS (1:1.500). A Região Nordeste concentrou $13,59 \%$ do total de CD e 4,22\% dos especialistas de todo o Brasil. As especialidades com maior concorrência nessa região foram Ortodontia, Endodontia e Prótese Dentária (Sanchez et $a l, .2008)$.

Outro estudo, de caráter regional, foi realizado na região Sul do País. Os estados dessa região apresentaram relação $\mathrm{CD}$ /habitante maior que o recomendado pela OMS. A região concentrou $15,76 \%$ do total de cirurgiões-dentistas de todo o Brasil e 8,95\% do total de especialistas. As especialidades com maior concorrência na região foram ortodontia e prótese dentária. Houve predominância de especialistas do gênero feminino 52\% (Paranhos et al,. 2009b).

Estudo semelhante foi realizado na região Sudeste do Brasil. Todos os estados apresentaram proporção acima do recomendado ela OMS. A região estudada concentrou $56,16 \%$ dos especialistas do Brasil. O mercado de trabalho para o especialista nesta região apresentava-se com menor concorrência nas áreas de Prótese Buco-maxilo-facial, Odontogeriatria, Patologia Bucal, Odontologia do Trabalho e Estomatologia. Ressaltaram o crescimento das mulheres no mercado odontológico, tanto generalista, como especialistas (Paranhos et al,. 2009c).

Com relação à região Norte do Brasil, os estados do Acre, Amazonas, Amapá e Pará possuíam proporção $\mathrm{CD} /$ habitante inferior à sugerida pela OMS (1:1.500). Por sua vez, Rondônia, Roraima e Tocantins estavam com mais dentistas do que o recomendado. Especialistas das áreas de Prótese Bucomaxilofacial, Odontogeriatria, Patologia Bucal, Odontologia para Pacientes com Necessidades Especiais, Odontologia do Trabalho e 
Estomatologia eram em menor número. Em contrapartida, Ortodontia e Endodontia apresentaram maior proporção especialista/habitante (Paranhos et al,. 2009d).

Em relação à região Centro-Oeste do Brasil, os três Estados apresentaram índices maiores que o recomendado pela OMS (1:1. 500). Essa região concentrava 7,98\% do total de CD e 5,32\% dos especialistas de todo o Brasil. As especialidades com maior concorrência nesta região são Ortodontia e Prótese Dentária. Por sua vez, Prótese Buco-maxilo-facial, Odontologia Legal e Patologia Bucal apresentaram menor proporção de especialista/habitante (Paranhos et al,. 2009e).

\section{Satisfação, formação e condições de trabalho}

Trabalho avaliou as ambições e preparo dos acadêmicos de duas faculdades de odontologia para trabalhar na ESF. Foram aplicados questionários individuais por um único pesquisador. Prevaleceu o desejo dos respondentes de trabalhar nessa estratégia, por razões ligadas às dificuldades do mercado de trabalho privado. Em uma das faculdades pesquisadas houve diferença estatisticamente significante na questão relacionada ao preparo do profissional para trabalhar no SUS. Os pesquisadores relacionaram essa característica ao internato rural oferecido por essa instituição (Sanchez, 2008).

Os aspectos administrativos e operacionais das Equipes de Saúde Bucal (ESB) da ESF foram pesquisados no Estado de Minas Gerais, com utilização de questionário, junto às Secretarias Municipais de Saúde, em 2004. 66,9\% dos municípios relataram formas de contratação precárias, sem a devida estabilidade no cargo exercido, a exemplo da indicação política e contrato temporário. Apenas 33\% relataram vínculos estáveis, com a garantia dos direitos trabalhistas. Também foi possível identificar grande diferença salarial entre médicos e dentistas. Os CD recebiam em média, menos de 50\% do salário pago ao médico, para o cumprimento da mesma carga horária. Ainda identificaram vulnerabilidades, como inadequada capacitação das ESB, demanda excessiva por atendimentos e a falta de entrosamento entre as equipes de saúde bucal e saúde da família (Lourenço et al,. 2009).

Foi realizada pesquisa em Santa Catarina acerca da satisfação no trabalho entre CD, atuantes da rede de atenção básica tradicional e da ESF, conduzida por meio de entrevistas. Em geral, o CD, além de ocupar 20 horas (da rede) ou 40 horas (ESF) do seu tempo semanal 
de trabalho dedicado ao serviço odontológico público, ainda atuava no setor privado em clínicas ou consultórios, com média de 12 horas de trabalho diário. Ressaltaram a relação direta entre remuneração insuficiente no serviço público, a formação para uma profisssão de caráter liberal e o sofrimento relacionado à sobrecarga de trabalho. No serviço público há uma relação direta com o sofrimento emocional relacionado à impotência do profissional diante da carência da população. O mercado de trabalha mais competitivo e carga horária excessiva foram associados a sofrimento do CD (Góes et al,. 2010).

Pesquisa realizada em 2009 observou a inserção dos recém-formados da Universidade Federal do Ceara em odontologia no mercado de trabalho, por meio de um questionário feito a 41 profissionais. Desse total, 32 (78,0\%) foram do sexo feminino e 9 (21,9\%), do sexo masculino. A faixa etária dos egressos foi de 22 a 28 anos de idade. $(60,9 \%)$ possuíam renda mensal de 3 a 5 salários mínimos, com uma jornada de trabalho de 31 a 40 horas por semana. $(46,5 \%)$ atuavam no setor público. $95 \%$ conseguiram se inserir no mercado de trabalho nos primeiros meses, concluindo que o mercado de trabalho no estado do Ceará não estava saturado. Os CD perceberam o mercado de trabalho como bom e normal e ainda mostraram-se satisfeitos com a profissão escolhida (Pinheiro et al,. 2011).

Com o objetivo de traçar o perfil do CD e verificar o exercício profissional na Atenção Primaria à Saúde (APS), no SUS do município de Montes Claros, Minas Gerais, Brasil, foi realizada pesquisa, com coleta de dados feita por meio de um questionário com $94 \mathrm{CD}$, abordando variáveis do perfil e exercício profissional. $61,7 \%$ dos entrevistados foram do sexo feminino, tendo 40,4\% desses entre 25 a 34 anos de idade. 36,2\% da amostra foi composta por formados há menos de dez anos e 47,9\% estavam trabalhando na ESF. A maioria relatou não apresentar dificuldades na função, devido ao fato de terem recebido treinamento em serviço e se formado recentemente (Giatti e Barreto, 2011).

Com o objetivo de analisar o perfil do $\mathrm{CD}$, dos Centros de Especialidades Odontológicas (CEO) com melhor e pior desempenho do Brasil, pesquisadores avaliaram, em 2009, as relações de trabalho vigentes dos profissionais, em 51 municípios de cinco macrorregiões. Foram pesquisados $59 \mathrm{CEO}$, por meio de aplicação de questionários. Foi constatada predominância do sexo feminino (55\%). A faixa etária predominante foi entre 30 a 49 anos de idade. $72,7 \%$ tinham cursado ou estavam cursando a pós-graduação, com predomínio da especialização (86\%). A maioria dos CD (58\%) atuavam no CEO em sua área de especialidade. Apesar dos CD que trabalham no CEO, serem qualificados, a remuneração 
foi considerada baixa. Ressaltaram ser crescente o número de mulheres no setor (Coelho et $a l, .2015)$.

\section{Discussão}

O mercado de trabalho vem mudando, o que exige atualização constante por parte do CD. Ultimamente houve uma ampliação postos de trabalho para o CD no SUS, especialmente na ESF, a partir de 1994, mas em contrapartida, houve criação de novas faculdades de Odontologia, com grande contingente de profissionais formados a cada ano. O mercado está saturado, especialmente em grandes centros. O crescimento populacional é bem inferior ao ingresso de novos CD, aumentando a competitividade no mercado a cada ano (Paranhos et al,. 2009e).

Apesar do grande número de $\mathrm{CD}$, ainda existem regiões com possibilidade de agregar novos profissionais, especialmente em locais com menor desenvolvimento e menor concentração da população. Uma das principais causas para a má distribuição dos CD generalistas e especialistas está na má distribuição das faculdades de odontologia, pelo Brasil (Paranhos, et al,. 2009a). Registraram-se a distribuição de faculdades de odontologias nas Regiões do Sudeste do Brasil concentra (50,52\%), Região Sul (15,96\%), Região Norte $(10,11 \%)$, Região Nordeste $(15,96 \%)$ e a Região Centro-Oeste $(7,45 \%)^{10}$. Consequência das autorizações das aberturas indiscriminadas de novos cursos, feita pelo Ministério da Educação, fruto da mercantilizarão do ensino no Brasil (Paranhos et al,. 2009c).

A má distribuição ainda é observada nos cursos de especialização, concentrados no Sudeste (Paranhos, et al,. 2009). Os profissionais tendem a buscar o trabalho em grandes centros ou se fixarem próximo à região onde cursaram o ensino superior, por fatores como a facilidade de cursos de especializações (Paranhos, 2009a). Isso favorece ao exercício ilegal da profissão em locais pouco acessíveis e mais carentes (Paranhos, et al,. 2009b).

Com o mercado saturado, aumenta a competição desleal e antiética do profissional, o que dificulta a conquista e fidelização dos pacientes nos consultórios odontológicos. A baixa procura por assistência odontológica se deve ao baixo poder aquisitivo da população. Assim sendo, os profissionais vêm explorando outras formas de remuneração, aliando por exemplo o 
trabalho no setor público, com o trabalho na clínica privada, o que inclui o atendimentos por planos de saúde (Paranhos, et al,. 2009a). Isso contribui para piora da qualidade de vida e insatisfação do profissional com sua carreira (Gomes, et al,. 2010). Além da redução da remuneração da profissão, vem ocorrendo a perda de prestígio social da Odontologia.

Hoje as mulheres dominam o mercado de trabalho em Odontologia (Paranhos, et al,. 2009e).Salienta-se que até a década de 80, havia o predomínio do gênero masculino. A presença feminina na profissão é crescente. A mulher além de ter conquistado o mercado de trabalho odontológico, ainda tem suas atividades domésticas, o que gera muitas vezes uma sobrecarga de atividades, com piora da qualidade de vida.

\section{Conclusões}

O mercado de trabalho em Odontologia vem se tornando mais competitivo, devido ao elevado número de profissionais $\mathrm{CD}$, acima do preconizado pela Organização Mundial de Saúde. Predomina o gênero feminino e vem crescendo o número de especialistas. O dentista precisa se capacitar continuadamente para atender as necessidades do mercado, pois é grande a concorrência na profissão. O governo precisa atuar de forma mais ativa na regulação da formação dos profissionais, para atender as necessidades de saúde da população.

Ressaltam-se limitações na presente pesquisa, como o pequeno número de estudos elegíveis, o que demonstra lacunas no conhecimento nessa temática. Novos estudos devem ser estimulados, tendo em vista a concentração de estudos em 2009 e a necessidade de conhecer as mudanças no mercado de trabalho atual.

\section{Referências}

MATHIAS MP, CASANI E, SAGAZ SM, LUCIETTO DA. Oferta de Cirurgião-Dentista do Brasil. Passo Fundo, RS, 2016.

MACHADO MH, MÉDICI A, NOGUEIRA RP, GIRANDI SN. O mercado de trabalho em saúde no Brasil: Estrutura e. Conjuntura. Rio de Janeiro: ENSP; 1992. 
PINHEIRO VC, MENEZES LMB, AGUIAR ASW, MOURA WVB, ALMEIDA MEL, PINHEIRO FMC. Inserção dos egressos do curso de odontologia no mercado de trabalho. Porto Alegre: Rev. Gaúcha Odontol. 2011. 59(6): 277-283.

BRASIL, Constituição (1988). Constituição da Republica Federativa do Brasil. Brasília, DF, Senado: 1988.

CONSELHO NACIONAL DE EDUCAÇÃO. Resolução CNE/CES 3 . Institui Diretrizes Curriculares Nacionais do Curso de Graduação do Curso de Odontologia. Brasília: CNE/CES, 2002.

FARIA, H.X; ARAÚJO, M.D. Preconização do trabalho e Processo Produtivo do Cuidado. Londrina -PR. 2011. V16. N1. P42

SANTOS, A. ASSIS, MM. Processo de Regionalização da Saúde m a Bahia: Aspectos Politicos-Institucionais e Moldagem dos Territórios Sanitários. V 13, n. 2 p.400-402, maiago/2017, Taubaté - SP, Brasil.

LUCIETTO DA, FILHO AA, OLIVEIRA SP. Revisão e discussão sobre indicadores para a previsão de demanda por cirurgiões-dentistas no Brasil. Porto alegre-RS, 2008.

PARANHOS LP, RICCI ID, SIQUEIRA MA, JUNIOR ED. Analise do mercado de trabalho odontológico na região Nordeste do Brasil. Revista de Odontologia da Universidade Cidade de São Paulo. São Bernardo dos Campos - SP, 2009.

PARANHOS LR, RICCI ID, SIQUEIRA DF, SCANAVINI MA, JUNIOR ED. Analise do mercado de trabalho odontológico na região Sul do Brasil. Rev. da Faculdade de Odontologia. São Bernardo dos Campos - SP, 2009.

PARANHOS LR, RAMOS AL, SCANAVINI MA, RICCI ID. Analise do mercado de trabalho odontológico na região Sudeste do Brasil. Res. Assoc. Paul. Cir. Dent. São Bernardo dos Campos- SP, 2009.

PARANHOS LR, RICCI ID, FILHO RPA, CASTRO R, SCAVANI MA. Análise do mercado de trabalho odontológico na região Norte do Brasil. Revista Odonto. São Bernardo dos Campos - SP, 2009.

PARANHOS LR, RICCI ID, BITTAR TO, SCANAVINI MA, RAMOS AL. Análise do mercado de trabalho odontológico na região Centro-Oeste do Brasil. Robrac. São Bernardo dos Campos - SP 2009.

SANCHEZ HF, DRUMMOND MM, VILAÇA RL. Adequação de recursos humanos ao PSF: percepção de formandos de dois modelos de formação acadêmica em odontologia. Belo Horizonte, MG, 2008. 
LOURENÇO EC, SILVA ACB, MENEGHIN MC, PEREIRA AC. A inserção de equipes de saúde bucal no Programa Saúde da Família no Estado de Minas Gerais. Piracicaba-SP, 2009.

GOMES D, GONÇALVES ASR, PEREIRA LS, TAVARES RS, PIRES DEP, RAMOS FRS. Satisfação e sofrimento no trabalho do cirurgião-dentista. Passo fundo-RS 2010.

PINHEIRO VC, MENEZES LMB. AGUIAR ASW, MOURA WVB, ALMEIDA MEL, PINHEIRO FMC. Inserção dos egressos do curso de odontologia no mercado de trabalho. Porto Alegre - RS, 2011.

COELHO MQ, COSTA SM, MARTELLI DRB, JUNIOR HM, BONAN PRF, FRANCY S. A Odontologia no contexto do Sistema Único de Saúde de Montes Claros, Minas Gerais, Brasil. Belo Horizonte- MG, 2011.

OLIVEIRA RS, MORAIS HMM, GÓES PSA, BOTAZZO C, MAGALHÃES BG. Relações contratuais e perfil dos cirurgiões dentistas em centros de especialidades odontológicas de baixo e alto desempenho no Brasil. São Paulo - SP, 2015.

Como citar este artigo (Formato ABNT):

COSTA, Danilo S.; ROCHA, Marcelo P da. O Cirurgião-Dentista e o Mercado de Trabalho no Brasil: Uma Revisão Sistemática da Literatura. Id on Line Revista Multidisciplinar e de Psicologia, 2017, vol.11, n.38, p.102-114. ISSN: 1981-1179.

Recebido: 16.10 .2017

Aceito: 18.10 .2017 